\title{
The connection of inertia rotary moment with the chromatographic retention time in alkanes series. New retention indices
}

\author{
C Igor S. Borisevich, ${ }^{1,2}$ Anastasia K. Vinogradova, ${ }^{1}$ \\ Viktor M. Pojidaev, ${ }^{2+}$ and Eugeny N. Ofitserov ${ }^{1{ }^{*}}$ \\ ${ }^{1}$ D.I. Mendeleev University of Chemical Technology of Russia. Miusskaya Sq., 9. \\ Moscow, 125047.Russia.Phone:+7 (499) 978-86-60.E-mail:ofitser@mail.ru \\ ${ }^{2}$ Complex of NBICS Technologies. National Research Center «Kurchatov Institute». Akademika Kurchatova \\ Sq., 1. Moscow, 123182. Russia.Phone: +7 (499) 196-71-00.E-mail: pojidaev2006@yandex.ru.
}

*Supervising author; ${ }^{+}$Corresponding author Keywords: gas chromatography, rotary motion inertia moment, retention time, retention index, Kovats index, chromatographic $\mathrm{I}_{\mathrm{J}}$ index, even and odd alkanes series properties.

\begin{abstract}
Earlier it was shown that cause of physicochemical properties oscillation and splitting into even and odd groups in the organic compounds homologous series is the rotational motion energy, determined by the molecule structure. In turn, the organic compound structure can be numerically described or expressed in terms of rotational motion inertia moment. It was logical to assume the correlation between the retention time and rotational motion inertia moment. In order to establish the connection of molecule rotational inertia moment with the chromatographic retention time, a mixture of normal structure alkanes $\left(\mathrm{C}_{6}-\mathrm{C}_{17}\right)$ was experimentally analyzed and corresponding graphs were constructed confirming the assumptions made. A new chromatographic index $\mathrm{I}_{\mathrm{J}}$ was proposed, which has advantages over the Kovats index $\left(\mathrm{I}_{\mathrm{K}}\right)$.
\end{abstract}

\section{References}

[1] E. Kováts. Gas chromatographische Charakterisierung organischer Verbindungen. Teil 1: Retentionsindices aliphatischer Halogenide. Alkohole, Aldehyde und Ketone. HCA. 1958. Vol.41. P.1915-1932.

[2] H. Van Den Dool, P. Dec. Kratz. A generalization of the retention index system including linear temperature programmed gas - liquid partition chromatography. J. Chromatogr. A. 1963. Vol.11. P.463-471.

[3] F.P. Woodford, M. Van gent. Gas-liquid chromatography of fatty acid methyl esters: the "carbonnumber" as a parameter for comparison of columns. J. Lipid. Res. 1960. Vol.1. P.188-190.

[4] G. Garzó, G. Alexander. Gas chromatographic retention characteristics of low molecular weight linear, cyclic and polycyclic methylpolysiloxanes. Chromatographia. 1971. Vol.4. P.554-560.

[5] O. Podlaha, B. Töregård. A system for identification of triglycerides in reversed phase HPLC chromatograms based on equivalent carbon numbers. J. High Resol. Chromatogr. 1982. Vol.5. P.553-558.

[6] A. Orav, K. Kuningas, S. Rang. A comparison of different retention index systems with unsaturated and aromatic hydrocarbons in capillary gas chromatography on PEG 20M. Chromatographia. 1993. Vol.37. P.411-414.

[7] G. Castello. Retention index systems: alternatives to the $n$-alkanes as calibration standards. $J$. Chromatogr. A. 1999. Vol.842. No.1-2. P.51-64.

[8] N.I. Tsarev, V.I. Tsarev, I.B. Katrakov. Practical gas chromatography. Teaching aid for students. Barnaul: Publishing House of Altai University. 2000. P.17-18. 156p. (russian)

[9] F.S. Calixto, A.G. Raso. Correlations between Van der Waals' volume and retention index general equation applicable to different homologous series. Chromatographia. 1981. Vol.14. P.596-598.

[10] F.S. Calixto, A.G. Raso. Retention index, connectivity index and Van der Waals' volume of alkanes (GLC). Chromatographia. 1982. Vol.15. No.8. P.521-524.

[11] E.N. Ofitserov, Yu.V. Vlasenko, and V.G. Uryadov. Numerical characteristic of the structure of organic molecule. Part 14. Study of interrelationship between the temperatures of phase transitions of a series of normal structure alkanes with the inertia moments of rotational motion. Butlerov Communications. 2011. Vol.26. No.10. P.12-25. ROI: jbc-02/11-26-10-12

[12] E.N. Ofitserov, Yu.V. Vlasenko, and V.G. Uryadov. Numerical characteristic of the structure of organic molecule. Part 13. Interrelation of the geometry of normal structure alkanes with the inertia moments of rotational motion. Butlerov Communications. 2011. Vol.26. No.10. P.1-11. ROI: jbc-02/11-26-10-1 